\title{
CASE STUDIES FROM DIFFERENT TYPES OF HEAT EXCHANGERS TO PLATE AND SHELL HEAT EXCHANGER: A REVIEW
}

\begin{abstract}
V. F. Bandeira,
W. M. Pachekoski, and A. Mikowski

Universidade Federal de Santa Catarina Programa de Pós-Graduação em Engenharia e Ciências Mecânicas Laboratório de Modelagem e Análise de Dados Dona Francisca, 8300, Joinville, Santa Catarina, Brasil vitor.vfb@gmail.com

Received: March 13, 2020 Revised: April 14, 2020 Accepted: May 15, 2020
\end{abstract}

\section{INTRODUCTION}

Different types of heat exchangers are generally described in terms of their constructive geometries. Among these, the tubular, plate and extended surface types are the most notable (Kakaç, 2012).

The Plate and Shell Heat Exchanger (PSHE) features, in its core, a rounded corrugated plate construction housed in a pressure vessel.

This equipment represents the combination of the best qualities of plate \& frame and shell \& tube heat exchangers. The first one has a high heat transfer rate, is compact and generates low fouling. However, it is composed of many seals and presents limitations of pressure and temperature. The second one operates at high pressures and temperatures, has no gaskets and has small pressure drops, however, the heat transfer rates are lower, the equipment is heavy and requires space, besides it produces a lot of fouling.

In summary, PSHE has a wide range of operation; high design pressures; wide heat transfer area; and may be employed in liquid/liquid, liquid/gas and gas/gas combinations. These characteristics combined with the low weight and volume compared to most commonly used exchangers is why this type of equipment is being largely used in offshore installations - in the oil and gas industry.
The corrugated plates, produced in various materials and diameters, are joined by welds and arranged in the shell, through which will flow a liquid or gas fluid that will run through the outer surface of the plates. Meanwhile, another fluid will flow between the plates. In this way, the fluids do not mix and take advantage of the entire surface area of the plates for heat exchange.

The heat exchangers in question are very versatile as to the type of material used in their manufacture. That is, the shell and the plates of the exchanger can be manufactured in different materials, to obtain a piece of more efficient and robust equipment.

AISI 316L, AISI 904L, 254 SMO, Hastelloy, Duplex, Titanium and Nickel are the main materials used to manufacture the corrugated plates of the exchanger, according to the catalog of a manufacturer of this type of equipment (Spirax-Sarco, 2017). These plates are made of thin metal sheets, on which the desired undulations are pressed. Further, in this article methodology, the focus of the research is directed to plates manufactured with the materials: AISI 316L and Titanium (more specifically titanium grade 1) since these are common choices in Brazilian oil rigs.

Pedrotti et al. (2015) and Scariot et al. (2005), as some articles, discuss the design aspect of 
exchangers considering heat transfer rate and components array. This work's central point is to investigate the problems encountered in the material selection phase of design. Considering that PSHE has reported failures in a short operating period.

The general objective of this work is to present a theoretical survey, whose content includes introductory material on the field of research, and, through case studies, material for analysis and decision making regarding the design and maintenance of a PSHE exchanger. In the development of this objective, it is proposed as specific objectives: to apply a research methodology; understand the phenomena related to structural failure in heat exchangers; evaluate case studies of different types of heat exchangers and obtain useful conclusions to the PSHE type; and, finally, to investigate advances in the area of plate \& shell type exchangers.

\section{RESEARCH METHODOLOGY}

In this work, aiming the description of concepts and techniques of analysis applied to the PSHE exchanger, a survey of publications on the heat exchanger theme was done, following the Systematic Literature Review (SLR) researched methodology.

According to Marconi and Lakatos (2013), data collection is the first step of any scientific research. Scientific rigor, however, requires such a survey to be systematic. Thus, an SLR is defined by Higgins and Green (2008) as a standardized search method, whose purpose is to answer certain research questions, through predefined eligibility criteria.

The research was conducted on three platforms: Scopus, Science Direct and Scielo.

The methodology used here consists of grouping keywords of a broader domain with words that describe the specific interests of the research, that is, it starts from a more general context to a more particular one. Another point considered to make this combination is not to use too many words or too restrictive words so that important results are not lost.

Therefore, one can define three contexts in which the keywords would fit. The first must define the equipment. Next, we indicate what we want to study about the equipment; and, finally, a characteristic or specificity of the study context is pointed out.

Combined keyword sets are listed below:

1. Heat Exchanger AND PSHE;

2. Heat Exchanger AND Mechanical Behavior;

3. Heat Exchanger AND Mechanical Behavior AND Titanium;

4. Heat Exchanger AND Mechanical Behavior AND Titanium Grade 1;

5. Heat Exchanger AND Mechanical Behavior AND Stainless Steel;

6. Heat Exchanger AND Mechanical Behavior AND Stainless Steel 316L;
7. Heat Exchanger AND Material Analysis;

8. Heat Exchanger AND Material Analysis AND Titanium;

9. Heat Exchanger AND Material Analysis AND Titanium Grade 1;

10. Heat Exchanger AND Material Analysis AND Stainless Steel;

11. Heat Exchanger AND Material Analysis AND Stainless Steel 316L.

At this point in the paper, it is worth mentioning that the searches performed on the Scopus platform considered titles, abstracts and keywords of articles published in indexed journals. However, the searches in the Science Direct database contemplate all the available fields in the site. The obtained results - raw data - were subsequently filtered. The number of data considered in function of each set of keywords can be observed in Figure 1.

Among the criteria used to perform the first filter, we can cite the following: the preference given to articles with less than 15 years, that is, published since 2005; the exclusion of conference reviews, journal notes and non-peer-reviewed articles; and, when appropriate, restricted the search to materials field journals.

The same procedure was applied to the Scielo platform, however, no relevant results were obtained for the research objectives with the set of established keywords. It was then decided to perform a more general search with only the keyword: "Heat Exchanger". 102 results were found, none of which were selected because they did not fit the search scope. Scielo obtained fewer results compared to the other platforms because it is limited to publications in Latin America.

As for the second filtered results, it is important to understand that the number of articles selected may present articles or dissertations repeated from one platform to another.

Note that the more specific combinations of keywords did not produce results on the platforms, which demonstrates the importance and originality of the work that will be done.

Knowing that failure modes in this type of structure are related to welded regions, one ambition of this survey is to obtain information about the welded region between plates of the heat exchanger PSHE, so new research was done with this approach. In this new phase of research, the following keyword combinations were used:

12. Heat Exchanger AND Weld*;

13. Heat Exchanger AND Plate Weld*;

14. Heat Exchanger AND Plate Weld* AND Laser;

15. Heat Exchanger AND Plate Weld* AND Plasma.

It is observed in Figure 1 that many studies were carried out with emphasis on the evaluation of welds in heat exchangers. 


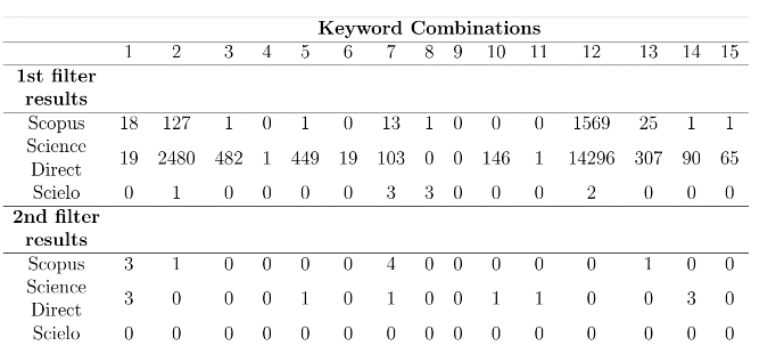

Figure 1. SLR results illustration.

Finally, the first results pointed out 19 works. Furthermore, a final selection was done and the SLR consists of 12 articles, one dissertation and one book.

\section{SLR RESULTS AND DISCUSSION}

It is noted that, with the data presented in the Methodology, applied in the period of June 2020, the field of research is relatively new and little explored. This justifies directing these case studies not only for plate and shell types of heat exchangers but also for other types of exchangers with similar structure, materials and operation features; highlighting exactly what is common to all of them, particularly concerning their use, maintenance and fault analysis. The main results of the theoretical research are divided according to the failure modes observed in the articles. It should be borne in mind that, in many cases, the failures of the structure occur from the combination of distinct processes. However, first, the work will highlight some articles with contributions to the field of research established.

\section{Contributions to the research field}

The first plate and shell exchanger was commercially produced by the Vahterus company in the 90s and is now produced by all major plate type exchanger companies. The possible shapes of corrugations in the plates of this type of exchanger are discussed by Arsenyeva et al. (2016), as well as possible path organizations within the heat exchanger. This author and her co-workers discuss the theoretical developments in the design of welded plate exchangers and compare plate \& shell and compabloc exchangers (another type of welded plate exchanger). It is worth mentioning the work carried out by Freire and Alves de Andrade (2014), which investigated the applicability of a PSHE in a nuclear reactor plant in the naval field. The authors point out that for this application, necessarily, limitations in volume and weight for the equipment are considered, which reaffirms the use of this type of compact technology by the offshore industry. Moreover, Freire and Alves de Andrade (2014) proposes a technique that can be used to investigate, through the finite element method (FEM), the efforts sustained by the welding region of two corrugated plates. The authors examined whether the mechanical stresses caused by pressure between the plates are acceptable according to the corresponding ASME standard. In the FEM model, an external pressure of $16.6 \mathrm{MPa}$ and an internal pressure of $6.45 \mathrm{MPa}$ were applied. The symmetry boundary conditions were applied to all other surfaces of the model. The mesh used had a total of 61,139 nodes and 377,778 elements. The results of the numerical simulation did not reveal points in which the maximum tension exceeded the internal pressure convenient to the authors' design, that is, $140 \mathrm{MPa}$.

One important point that will be mentioned during the presentation of the case studies is the fouling problem in heat exchangers. According to the manufacturer (Vahterus, 2019), the PSHE has a low fouling rate. However, such deposition of suspension substances in the fluids (or precipitation of dissolved solids, which may become insoluble solids due to the increase in temperature) is still observed in the PSHE and should vary according to the operating conditions of the equipment.

The fouling in plate exchangers occurs according to the geometry and velocity of the fluid (Abu-Khader, 2012). Also (Kho and MullerSteinhagen, 1999) observed that the fouling process occurred at different rates under identical operating conditions. The authors attribute this to the effect of the flow distribution between plates. Grandgeorge et al. (1998) carried out an experimental study of the formation of liquid phase particulates in a plate exchanger made of stainless steel. These are important parameters to define the equipment lifecycle since they influence in corrosive processes.

From now on, concepts and techniques applied to other types of heat exchangers, in the case studies, will be appreciated and, when possible, adapted to the PSHE exchanger.

\section{Failure modes related to corrosive processes}

The work done by Xu et al. (2015) deals with a tubular type heat exchanger. This model consists of a shell, usually a pressure vessel, with several tubes in it. Through investigating the operating conditions, analyzing the chemical composition of the material and corrosive products, and through metallographic tests of samples with the presence of cracks, the authors conclude that the failures in the equipment are a result of Stress Corrosion Cracking (SCC). The material corresponds to austenitic stainless steel. In this case, SCC can occur when this material is simultaneously subjected to an internal pressure, which induces stresses in the structure, and corrosive fluid.

Two tubes with the presence of faults were evaluated, one consisting of TP304H steel and the other TP304 steel (according to ASME notation). To evaluate the microstructure, metallography tests were performed by optical microscopy. As expected, both presented similar metallography. The microstructure 
corresponds to austenitic grains and some nonmetallic inclusions. Through this characterization test, the author could conclude that the fractures did not originate due to the deterioration of the material since there were no changes in the original metallographic structure.

Fractures schematics can be observed in Figure 2. The inner surfaces of the tubes exhibit corrosion and the fractures originated from this inner surface and propagated to the outer surface of the tubes.

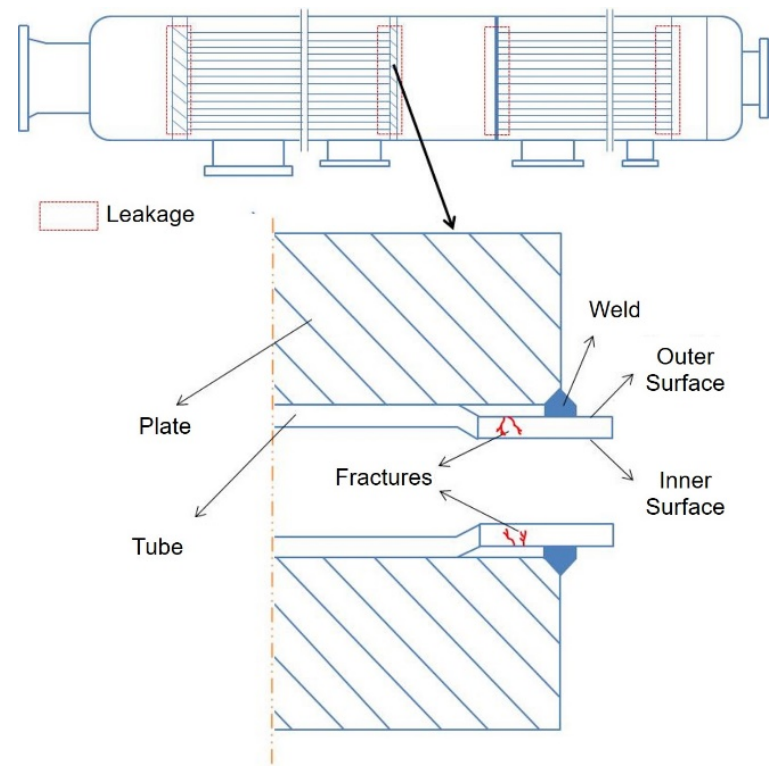

Figure 2. Fractures and leakages locations.

The chemical composition of the corrosive products was examined by Scanning Electron Microscopy (SEM), Energy Dispersive Spectrometer (EDS) and X-ray Diffraction (XRD). Through these tests, it was possible to conclude that the steam that passed through the tubes was contaminated by chlorine, and the reason for failure is the SCC of austenitic stainless steel in high-temperature steam containing chlorine.

For applications of heat exchangers in systems containing liquids in the temperature range between 0 and $90^{\circ} \mathrm{C}$, microbiological growth is not uncommon. Huttunen-saarivirta et al. (2012) studied the corrosive process influenced by the presence of microorganisms. A form of corrosion can be initiated or propagated, for example, by bacteria, algae and fungi. The author conducted the study with an AISI 304 stainless steel heat exchanger, with failures registered after three years of operation. Considerations are made regarding the presence of the austenitic and ferritic microstructures in this material and the preferential attack suffered by the ferritic phase. Microstructural characterization analyzes were performed by optical microscopy, SEM, EDS, transmission electron microscopy (TEM) and XRD.
In another article, Panahi et al. (2017) investigate failure in a heat exchanger of gasket plates. The plate material is 304 stainless steel. This exchanger operates in a natural gas treatment plant.

Natural gas is composed of a mixture of hydrocarbons and a certain amount of impurities $\mathrm{CO}_{2}, \mathrm{O}_{2}, \mathrm{~N}, \mathrm{H}_{2} \mathrm{~S}$ and $\mathrm{He}$ are the most common, according to Lopes (2003). These impurities can cause various operational problems in the plant, such as corrosion in ducts, and therefore must be removed. Among the various forms used in the removal of these contaminants, microemulsified systems with amines are used.

Now that the operating environment is understood, it should be kept in mind that this exchanger has failed in the gasket regions. However, unlike the other exchangers studied in this review, the joints of this exchanger are made by the elastomeric material. This fact does not invalidate the conclusions for fault prevention obtained by the author since these operating conditions and inherent corrosive processes also occur in welded plate exchangers. Panahi et al. (2017) conclude that the main reason for the failure observed was intergranular corrosion accompanied by high-stress levels in the joint region, which caused the cracks in this region of the heat exchanger. To prevent these types of failures, it is possible to: treat the impurities in another way, reducing the corrosivity of the operating environment; use a more recessive stainless steel, such as 316L (research focus); and control external sources of stress which, in the case of corrugated plate exchangers, may be due to adjustment of the tightening screws. In welded plate exchangers, these tensions can usually result from residual stresses in the weld region, as well as from other forms of stress concentration in the structure - discussed in the following topic.

\section{Failure modes related to stress concentration}

$\mathrm{Xu}$ and Wang (2013) performed numerical investigations of residual stresses in the welded region of a shell and tubes heat exchanger. A common problem in this type of equipment is the evolution of cracks in the weld between tubes and plates. The FEM was used to investigate the region of the weld under the condition of axisymmetry. The residual stress is calculated using as input data a temperature distribution, which is obtained employing a thermal analysis performed with the aid of the ABAQUS program. According to the authors, the properties of the material relevant for evaluating the residual stress are the elastic modulus, yield stress, Poisson coefficient and coefficient of thermal expansion. It was concluded that a discontinuous stress distribution was generated at the interface between the thermally affected zone and the base metal. The maximum residual von Mises stress occurs in the base metal close to this interface. 
Welding parameters such as welding energy, preheating temperature, joint distance and welded tube diameter have been studied and all change the residual stress values. However, the welding energy has little influence on the residual stress, since this mechanical property, when it reaches its maximum value, is determined by the fact that the yield limit for the base metal is higher than the yield limit for the weld region. This discrepancy between the yield limits causes an irregular residual stress distribution. It was also observed that, with the increase of the distance of the welded joint, there is an increase in the residual stress peak. Another important conclusion of this work, which can be extrapolated to evaluations of other types of heat exchangers, is that the increase of the preheating temperature corresponds to lower peak value for the residual stress.

At this moment, it should be noted that austenitic stainless steel, such as ASME 316L, has a high coefficient of thermal expansion and low thermal conductivity. For these reasons, when subjected to welding processes, it is especially susceptible to distortions during the process. Also, welds of $100 \%$ austenitic structure are more susceptible to cracks, and a percentage of ferritic phase is essential to control this susceptibility. In addition, in welds of austenitic stainless material, generally, small pools of delta ferrite are formed (Sing, 2012, p. 196-197).

Another study focusing on the welded region between tubes and tube plates was developed by Long et al. (2016), where the flaws are similar to those of the previously discussed article ( $\mathrm{Xu}$ and Wang, 2013). The 304 stainless steel tubes were welded to plates made of SA516 Gr.70 alloy. The welding process was MIG (Metal Inert Gas) without additional metal.

Through visual inspection, it was found that all cracks occurred within $10 \mathrm{~mm}$ of the welded region, including the $0.4 \mathrm{~mm}$ depth of the weld. The surface of the fractures in the tubes was perpendicular to the axial direction. The tubes were evaluated and characterized using a stereomicroscope, as well as SEM and EDS techniques. From these techniques, it was concluded that the fracture occurred without significant plastic deformation; that both the outer surface of the tube and the inner surface showed some corrosion, but no pitting corrosion was observed; the chemical composition close to a failure was confirmed and no corrosive agents such as chlorine and sulfur were present; it was found that the fractured surface is divided into two distinct zones: the lower region, close to the inner face of the tube, where the cracks occur; and the upper region, where the insufficient melting defect between tube and plate is observed. The interface between these areas showed a high concentration of tension and was the origin of the crack.
The XRD technique and Fourier Transform Infrared Spectroscopy (FTIR) proved that there was no modification in the metal composition in the failure region. To evaluate the microstructure of the material, a sample of the weld failure part and a control sample were prepared. Mechanical traction tests were performed on failure tubes and tensile strength limits were obtained. The yield stress and maximum deformation were consistent with the material standard. However, some values were higher than the standard, which may mean that the material is hardened and thus more fragile to resist this application.

Moreover, according to Long et al. (2016), both welding defects and severe expansion processes can cause stress concentrations in joints. To confirm the point of highest stress concentration, the authors performed a three-dimensional FEM analysis consisting of the tube, tube plate and welded region. The mesh consists of 96,553 knots and 57,282 elements, with a greater mesh refinement in the joint region. The result of the simulation demonstrates, considering the von Mises stress distribution, that the point of highest concentration coincides with the region of crack formation.

According to Long et al. (2016), there is evidence that suggests that the mechanism of failure in the region studied is due to the fatigue process established by periodic loads during the operation of the equipment. The author concludes that a fault weld, together with incorrect positioning of the expansion region of the tubes connected with the plates, collaborated for the formation of cracks.

In 2013, laser welding technology was not wellknown in the sector of heat exchanger manufacturing, according to Vandewynckéle et al. (2013). These authors discuss the introduction of this technology to shell and tube exchangers. It is worth mentioning that the main feature and advantage of laser welding is the ability to focus the energy delivered to the weld with high precision. That is, this process makes it possible to obtain high values of heat flow in a region of 0.2 to $0.6 \mathrm{~mm}$. As a result, a narrow fusion zone and low welding energy are observed. These factors can correspond to a reduction in rework operations, which also means lower costs of maintenance and repairs in the welded regions (Vandewynckéle et al., 2013).

As previously mentioned, during the research stage, the focus was given to titanium grade 1 and 316L steel. This is because they are materials widely used in the manufacture of welded corrugated plates for PSHE. The researchers in (Antony et al., 2014) elaborated a work that can serve as a basis to define certain parameters of laser welding in austenitic stainless steel. The authors performed numerical and experimental investigations on the laser casting of 316L stainless steel in powder form on a substrate layer of the same metal. 
The type of laser used was Nd:YAG (Neodymium-doped Yttrium Aluminum Garnet), the energy source was focused at the top of the surface and moved at a constant speed. The intensity of the laser can be described by a Gaussian distribution whose governing equation is determined as a function of laser power, laser beam radius, laser beam velocity and travel time.

ASME 316L stainless steel is an austenitic steel of CFC structure. An observation should be made regarding the presence of nickel in the chemical composition of these steels. It should be noted that nickel is a stabilizing element of the austenitic phase. This element acts by increasing the austenite field and, thus, virtually eliminates ferrite from ferrochromium-carbon alloys. This means that if the carbon content is below $0.03 \%$, the carbides do not form and the steel is composed of austenite at room temperature (Askeland and Phulé, 2008).

The Nd:YAG laser parameters were adjusted to raise the exposed area of the powder to a temperature sufficient for the particles to merge and form a dense layer. The effects of these parameters on the geometry, morphology and homogeneity of a single step welding process were analyzed and characterized by techniques such as: laser particle size analyzer, macro and microscopic inspection, SEM, XRD and FTIR.

In this paper, a FEM model for the heat transfer problem was developed to determine the temperature distribution in a single layer of powder. This modeling was used to understand the effect of the welding parameters on the geometrical characteristics of the final part, such as the thickness of the weld region.

\section{SUMMARY AND CONCLUSIONS}

This work aimed to describe researches in the field of heat exchangers, directing to a review of PSHE and its failure modes, also focusing on the structural and mechanical characterization models employed to obtain it. About the objectives of this research, it is believed that a theoretical basis of possible solutions applicable to heat exchangers whose failure modes are related to corrosive processes or stress concentration - could be established.

Panahi et al. (2017) presents a set of solutions for their case study that consists of changing the material (for a more recessive), reduce the corrosiveness of the operating medium and reduce external sources of tension. Case studies involving corrosion focused on assessing the same points of interest during the respective failure analyzes.

Seeing that the whole PSHE structure is welded special attention is necessary for the material selection and construction process since, according to Singh (2015), both welding defects and severe expansion processes can cause stress concentrations in heat exchanger joints.

Long et al. (2016) commented that a narrow melting zone and low welding energy result from the laser welding process. Thus, the use of this technique in joining the plates of the PSHE can reduce costs with rework operations, such as the need for the heat treatment of the structure, maintenance and repairs in the welded regions.

In the works carried out by Xu et al. (2015), Xu and Wang (2013), and Long et al. (2016), which involve the analysis of the mechanical behavior in the welded region, it was found that the elastic modulus was not determined. The nanoindentation technique, also known as instrumented indentation, can be an interesting and important alternative to estimate the elastic modulus, as well as the hardness, of the region of the weld (with micro and nanoscale precision) by the consolidated Method of Oliver-Pharr (Oliver and Pharr, 1992).

Finally, it was expected to obtain results regarding the application of titanium in the manufacture of the plates and to obtain case studies of exchangers using this material. However, within the limits of the theoretical survey made in this work, nothing so specific was found in the platforms researched.

\section{ACKNOWLEDGMENTS}

The Brazilian National Council for Research (CNPq) is acknowledged.

\section{REFERENCES}

Abu-Khader, M. M., 2012, Plate heat exchangers: recent advances. Renewable and sustainable energy reviews, Vol. 16, No. 4, pp. 18831891.

Antony, K. et al., 2014, Numerical and experimental investigations on laser melting of stainless steel 316L metal powders. Journal of Manufacturing Processes, Vol. 16, No. 3, pp. 345355.

Arsenyeva, O. P. et al., 2016, Two types of welded plate heat exchangers for efficient heat recovery in industry. Applied Thermal Engineering, Vol. 105, pp. 763-773.

Askeland, D. R., Phulé, P. P., 2008, Ciência e engenharia dos materiais. 1st ed., São Paulo, Cengage Learning, pp. 404-405.

Freire, L. O., Alves de Andrade, D., 2014, On applicability of plate and shell heat exchangers for steam generation in naval PWR. Nuclear Engineering and Design, Vol. 280, pp. 619-627.

Grandgeorge S. et al., 1998, Particulate fouling of corrugated plate heat exchangers. Global kinetic and equilibrium studies. Chemical Engineering Science, Vol. 53, No. 17, pp. 3050-3071. 
Higgins, J. P. T., Green, S., 2008, Cochrane Handbook for Systematic Reviews of Interventions.Tottenham.London: John Wiley \& Sons Ltd.

Huttunen-saarivirta, E. et al., 2012, Microbiologically influenced corrosion (MIC) in stainless steel heat exchanger. Applied Surface Science, Vol. 258, No. 17, pp. 6512-6526.

Kakaç, S. et al., 2012, Heat exchangers: selection, rating, and thermal design. 3rd ed., Boca Raton: CRC Press.

Kho, T., Muller-Steinhagen H., 1999, An experimental and numerical investigation of heat transfer fouling and fluid flow in flat plate heat exchangers. Chemical Engineering Research and Design, Vol. 77, No. 2, pp. 124-130.

Long, L. et al., 2016, Failure analysis of tube-totubesheet welded joints in a shell-tube heat exchanger. Case Studies in Engineering Failure Analysis, Vol. 7, pp. 32-40.

Lopes, F. W. B., 2003, Dessulfurização do Gás Natural Utilizando Sistemas Microemulsionados. Master Thesis, Universidade Federal do Rio Grande do Norte, Programa de Pós-Graduação em Engenharia Química. Natal, RN, Brasil.

Marconi, M. D. A., Lakatos, E. M., 2013, Técnicas de pesquisa. 7th. ed., São Paulo: Atlas, pp. 48.

Oliver, W. C., Pharr, G. M., 1992, An improved technique for determining hardness and elastic modulus using load and displacement sensing indentation experiments. Journal Materials Research, Vol. 7, pp. 1564-1583.

Panahi, H. et al., 2017, Failure analysis of type 304 stainless steel amine exchanger sheets in a gas sweetening plant. Case Studies in Engineering Failure Analysis, Vol. 9, pp. 87-98.

Pedrotti, V. A. et al., 2015, Constructal Design of a Tubular Array Subjected to Forced Convection. Thermal Engineering, Vol. 14, No. 1, pp. 16-21.

Scariot, M. R. et al, 2005, Simulation of the Temperature Profile of a Pectin Solution in a Plate Heat Exchanger: A Non-linear System Approach for Control. Thermal Engineering, Vol. 4, No. 1, pp. 3034.

Singh, R., 2012, Applied welding engineering: processes, codes, and standards. ButterworthHeinemann, pp. 196-197.

Spirax-Sarco. "Plates \& Shell" Heat Exchangers, New PSHE series. Retrieved: 25 Oct. 2017, from $<$ http://www.spiraxsarco.com/global/italy/Products/D ocuments/E\%20-

\%20Scambiatori\%20di\%20calore\%20a\%20piaste\%2 0e\%20mantello\%20PSHE_.pdf $>$.

Vahterus, Plate \& shell heat exchanger technology. Retrieved: 1 Jan. 2019, from <URL https://vahterus.com/products/>.

Vandewynckéle, A. et al., 2013, Laser welding head tailored to tube-sheet joint requirements for heat exchangers manufacturing. Physics Procedia, Vol. 41, pp. 144-152.

$\mathrm{Xu}$, S. et al, 2015, Failure analysis of stress corrosion cracking in heat exchanger tubes during start-up operation. Engineering Failure Analysis, Vol. 51, pp. 1-8.

Xu, S., and Wang W., 2013, Numerical investigation on weld residual stresses in tube to tube sheet joint of a heat exchanger. International Journal of Pressure Vessels and Piping, Vol. 101, pp. 37-44. 